\title{
Learning Mathematics with Intelligent Tutors: Gender Wise Similarity and Differences
}

\author{
Anita Dani
}

\begin{abstract}
ALEKS is a web-based intelligent tutoring system, which is used in the higher education institutes to teach post-secondary mathematics courses. The name ALEKS is an acronym for Assessment and Learning in Knowledge Spaces, which indicates that this software provides learning opportunities through frequent formative assessments. The purpose of this paper is to investigate similarities and differences between male and female students' study habits and perceptions about learning mathematics using this intelligent tutoring software. Results of independent samples t-test demonstrated that female students are more organized and follow systematic study habits more often than male students. Also the perceptions about the impact of ALEKS on their learning were found to be different in male and female students.
\end{abstract}

Index Terms - Intelligent tutor, ALEKS, mathematics education, gender wise differences.

\section{INTRODUCTION}

Most non-mathematics major students fail to appreciate the true nature of mathematics when they encounter endless drill exercises. The tediousness of problem solving can be removed with the help of appropriate use of technology and tools. The emergence of web-based technology and artificial intelligence techniques have resulted in the growth and evolution of teaching and learning of mathematics [1], [2]. It cannot be claimed that the use of technology will always result in effective learning, but its full potential can be achieved only if it is used appropriately. There always have been arguments in favour and against the use of technology in education.

Bates \& Poole suggest that "Learning through technology is not necessarily better or worse than face-to-face education; it is different" [3]. It is suggested by many researchers, that improved pedagogical models are needed to increase the effectiveness of mobile learning [4]-[7]. Computer aided instructions can integrate more than one medium, such as plain text, audio and video lessons. They can also provide authentic learning activities which can support many students at the same time in a classroom setting as well as outside the classroom. But computer supported tutoring is still not found to be as effective as human tutoring. Human tutoring is more effective than computer tutoring due to two parameters, which are ability to provide instant and appropriate feedback and adaptive scaffolding techniques. Human tutors provide scaffolding based on the ability of the student. In an attempt to achieve the same effect as human tutoring, efforts are

Manuscript received May 20, 2017; revised August 2, 2017.

Anita Dani is with the Higher Colleges of Technology, United Arab Emirates (e-mail: Anita.Dani@hct.ac.ae). being made to embed three

Characteristics of human tutors into the tutoring software, which are knowledge of the subject, knowledge of the student and knowledge of teaching [8]. Tutoring systems which embed these three characteristics with the help of techniques of artificial intelligence are known as intelligent tutoring systems.

Since intelligent tutors are developed with the aim of improving learning outcomes, developers of intelligent tutors work towards achieving the same effect as the expert human tutoring effect [9], [10]. Intelligent tutors provide superior performance than any other computer assisted instruction program because they are developed by combining theories of cognitive science and techniques of artificial intelligence [11]-[15]. These tutoring software systems make personalized tutoring widely and inexpensively available.

Theory of self-regulated learning postulates that learners are regulating their own learning by setting their learning goals. Further, they attempt to accomplish these goals by organizing their learning activities. It was found that students may enjoy learning with intelligent tutors, but in order to retain the mastery of their learning, they need to organize their learning activities as suggested by the theory of self-regulated learning [16].

Male and female students are found to exhibit different behavior patterns in online learning [17]. Kaino found by empirical investigation that girls and boys both agree that computers are useful, but girls had higher anxiety than boys [18] while using computers. The study presented in [17], was about the gender-wise differences in using computers in general, whereas empirical findings in the context of learning mathematics are reported in [19]. The author of this paper found that girls and boys did not show any difference in mastering numeric skills using mobile technology. There are not many empirical studies reporting gender differences in learning with intelligent tutor. Accepting the fact that there is a difference between these two modes of education, the current research investigates under which circumstances, learning mathematics with the help of mobile devices and an intelligent tutoring software can give better results.

The purpose of this research is twofold. This research examines under which conditions, students' learning with the help of an intelligent tutor, is improved. This research further examines the similarity and differences in the perceptions as well as study habits of male and female students.

This paper is organized into four sections. A brief literature review is presented in the section II, research context and methodology are given in the section III. The results of data analysis and discussion are presented in the section IV and the conclusion and future directions are given in the section V. 


\section{THEORETICAL FRAMEWORK AND LITERATURE REVIEW}

The investigations of this research are based on the Activity Theory framework which was initially introduced by Vygotsky. Vygotsky proposed that the association between a stimulus and the response given to it, is mediated by activities carried out with the help of some kind of artifacts [20]. These artifacts consist of tools and signs. Activity Theory framework has evolved from a simple first generation model proposed by Vygotsky to a more detailed second generation model developed by Engestrom [20]. According to the first generation model of Activity Theory, the following components together form a unit of analysis: Student (subject), mediating artifacts ( $a$ digital tool) and the learning goal (object). This framework allows to explore all types of interactions between the two main components, which are the student and the tool. Then it becomes easy to detect which of these interactions lead to the attainment of the goal.

The Activity Theory has been used not only in the field of human-computer interaction [21] but also in the field of mobile learning and mathematics education [22]-[27]. The first generation model of the Activity Theory has been applied for inestigating the proposed research questions as our research questions aim to understand the interactions between the students and the mobile device and the impact of these interactions on their learning.

Though the effectiveness of using mobile technology for learning mathematics has been confirmed by many researchers [2], some researchers also found that if a student believes that a computer can't help them learn (even though they do actually learn), then they have a high probability of disliking the system and becoming less motivated [28]. It may be necessary to examine the role of non-cognitive factors, such as beliefs and interest. While investigating phenomena of learning mathematics, it is important to understand affective constructs. Persistence, seeking external help and systematic efforts exhibited while interacting with the tool and while solving problems are some of the factors that constitute student's study patterns and these patterns are influenced by psychological constructs, such as affect [29]. The type of student's interactions with the tool must be examined within a context of learning activity which includes the learning community and the physical tools as well as the cognitive tools. For example, the physical tools may include the mobile devices, study notes and the cognitive tools may include the prior knowledge and beliefs about learning with the tool.

For appropriate development and deployment of online mathematics assessment and tutorial system, it is important to assess students' expectations and attitude about the software. Extensive research has been done on the use of the graphing calculator as a mathematics learning tool [30], [31]. There is a need to do a similar research on the use of an intelligent tutor to learn mathematics. This research will attempt to fill this gap by examining the current practices of using an intelligent tutor and exploring the student's patterns of interaction with the intelligent tutor.

\section{RESEARCH CONTEXT AND METHODOLOGY}

This research has been carried out in one of the higher education institutes which has 17 campuses in different Emirates in the United Arab Emirates. The students studying in the foundation year program from different campuses of this higher education institute participated in this research.

The students enrolled in the foundation year program are fresh high school graduates, graduating from public schools in the United Arab Emirates. Their English language proficiency levels are weak to moderate level. All participating students are learning English as their second language and majority of them are exposed to English medium of instruction for the first time. The majority of the students in this program is studying two subjects, foundation English and Mathematics, but some students who met the English eligibility criteria to join the degree programs, need to take foundation mathematics courses along with their major courses. These students use a laptop or an Apple MacBook, whereas foundation students who are studying Foundation English and Mathematics only, use iPads. All campuses of this institute are equipped with sophisticated and technology rich learning environment.

ALEKS is a web-based intelligent tutoring system, which is used in the chosen higher education institute to teach mathematics to students in the foundation program. The name ALEKS is an acronym for Assessment and Learning in Knowledge Spaces, which indicates that this software provides tutoring support and learning opportunities through frequent formative assessments. ALEKS provides sufficient practice material for each conceptual unit to master the concept and administers frequent formative assessments to provide feedback on learning. It predicts the probability of correctness of a student's next response based on the student's previous response. It mimics the ability of an expert teacher and can confirm whether the student has mastered a conceptual unit and whether the student has retained the achieved mastery. ALEKS has the ability to create individualized sequence of topics based on the student's background knowledge and level of cognitive development.

As established in the previous research [16] students who followed systematic study habits and interact with the intelligent tutor in an organized manner are more engaged in their learning. Taking notes, reading explanation are some of the systematic habits of studying and organizing learning tasks, setting goals are some of the systematic habits of using the intelligent tutor.

The aim of the research is broken down into two research questions as follows:

1) Do the systematic study habits, such as taking notes, reading the explanation, increase the effect of systematic use of the intelligent tutor on student's learning?

2) Do male and female students exhibit same study habits of male and female students?

These research questions are addressed using quantitative research approach. The quantitative data were collected using surveys. A total of 204 students participated in the survey, but three responses were incomplete. Out of 201 students 136 are females $(68 \%)$ and 65 are males $(32 \%)$. The approximate proportion of female and male students in the target population is $3: 1$. The proportion in the sample is consistent with the population proportion.

A survey instrument was designed to measure students' perceptions about the effectiveness of the intelligent tutor ALEKS. Some items in the survey are designed to measure the two factors representing skills of using ALEKS and 
understanding of mathematics. The skills of using ALEKS are measured by assessing students' perceived ease of using ALEKS and the effect of its tutoring on their learning. Whereas understanding of mathematics is measured by assessing their perceptions about learning. The student survey instrument also consists of items which measure students' preferences as well as perceived effects of using mobile devices and other learning resources. Some items of the survey are identified on the basis of students' study habits observed by the researcher in class while teaching the course over the past four semesters. The intelligent tutoring software ALEKS provides twofold support in learning mathematics; explaining mathematical concepts and tutoring support to master the concepts. Some items in the survey instrument are defined to measure students' perceptions about these two features of ALEKS. Effectiveness of ALEKS as a tool which develops understanding of mathematical concepts is termed as its cognitive effect while its effectiveness as a tool that provides tutoring support is termed as its tutoring effect. Students' beliefs and attitudes about ALEKS are measured as perceptions whereas students' ways of interacting with ALEKS and with peers are measured as study habits. The survey instrument is divided into two parts. The first part has 29 items measuring perceptions and beliefs using the Likert scale as 1: Strongly agree to 5: Strongly disagree. The second part consists of 15 items which measure the frequency of adapting a particular study habit. These items are measured on the Likert scale as 1: Always to 5: Never. The reliability of the items in both parts was found to be equal to 0.9 which indicate a high internal consistency of the instrument.

The principle component analysis method was applied for grouping the items into factors. Five factors were extracted from the items in both parts of the survey instrument. For each factor, the mean score of its components was calculated. The normality of the variables representing these factors was examined by applying the Kolmogorov-Smirnov test of normality. The results of this test indicated that these variables are not normally distributed, therefore path analysis was done because the methods of structural equation modelling are robust to the deviation from normality. The path analysis was done using the software AMOS. The maximum likelihood method was applied and bootstrapping was performed to get estimates of the regression weights along the paths. The Normed Fit index (NFI) and Comparative Fit Index (CFI) should be 0.9 or higher and p-value of the Chi square statistics should be $>0.05$. The Chi-square statistic value is 2.991 with a p-value 0.886 . Both the NFI and CFI values are found to be equal to 1 . These scores indicate that the model satisfies the conditions of goodness of fit and hence results produced are acceptable here.

An independent variable (denoted by $X$ ) can cause a dependent variable (denoted by $\mathrm{Y}$ ). The notation $X \rightarrow Y$ is used in a path model to indicate that there is a causal relationship between $\mathrm{X}$ and $\mathrm{Y}$. The causality can be examined by running the regression analysis. The regression weight is shown on the direct path between $\mathrm{X}$ and $\mathrm{Y}$. Third variable $\mathrm{M}$ can be caused by $\mathrm{X}$ and in turn, it can cause the variable $\mathrm{Y}$. If the regression weight along the direct path between $X$ and $Y$ is less than the total regression weight along the two paths $X \rightarrow M$ and $M \rightarrow Y$, then the variable $\mathrm{M}$ has a mediating impact on the association between $\mathrm{X}$ and $\mathrm{Y}$ [32]. The statement of the hypothesis stated in (a) indicates that the variable representing systematic study habits have a mediating effect on the association between the two variables representing systematic use of tools and the cognitive effect of the intelligent tutor. The first research question is analyzed using methods of mediation analysis, whereas the second research question is analyzed by applying non-parametric tests for comparing two independent samples. The details of data analysis are given in the next section.

\section{RESUlTS AND DisCUSSION}

The students can organize their learning activities while using ALEKS. For example, they do not choose the topics to master in a random sequence, they read the explanation and feedback carefully and review previously mastered topics regularly. These habits indicate habits of using ALEKS systematically.

A student's systematic study habits, such as taking study notes during the class discussion and solving problems step by step while using ALEKS, indicate active participation in learning and taking responsibility of own learning. This active engagement in learning may facilitate cognitive development.

It is hypothesized that adopting these systematic study habits more often while using ALEKS, will increase the impact of ALEKS on the development of mathematical knowledge. In this case, it should be examined if the variable SHabit1 representing the factor systematic study habits has any mediating effect on the association between the variables systematic use of tools (SHabit3) and the perceived tutoring effect of ALEKS (Factor 1). Refer to the path model in Fig. 1.

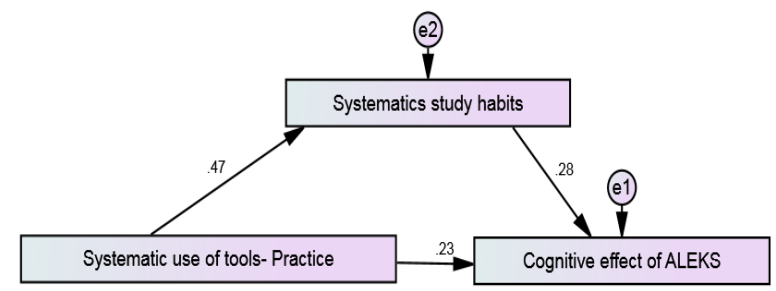

Fig. 1. Path model showing the mediating effect of systematic study habits.

For the first research aim (a) the null and alternate hypotheses are set as follows:

$\mathbf{H 1}_{\mathbf{0}}$ : Systematic study habits do not change the effect of systematic use of tools on the perceived cognitive effect of ALEKS. (The variable SHabit3 has no mediating effect on the association between the variables SHabit1 and Factor1.)

$\mathbf{H 1}_{\mathbf{A}}$ : Systematic study habits improve the effect of systematic use of tools on the perceived cognitive effect of ALEKS.

Refer to the Table I which shows the standardized direct and total effects. The mediating effect of a variable is established if the total effect of the variable Shabit 3 is greater and significant than its direct effect on the variable Factor1 [33].

From the Table I, it can be seen that the total effect of SHabit3 on Factor1 $(r=0.360$, Sig=0.00) is greater and significant than the direct effect of SHabit3 on Factor1 $(r=0.160, \mathrm{Sig}=0.42)$. Therefore, there is an evidence to 
reject the null hypothesis and accept the alternate hypothesis confirming that systematic study habits improve the effect of systematic use of tools on the perceived tutoring effect of ALEKS. (Note: $* * *$ in AMOS output indicates a very small value).

\begin{tabular}{lllll} 
TABLE I: STANDARDIZED DIRECT AND TOTAL EFFCTS-HYPOTHESIS 1 \\
\hline Indicated path & $\begin{array}{l}\text { Estim } \\
\text { ate }\end{array}$ & $\mathrm{P}$ & $\begin{array}{l}\text { Standard } \\
\text { ized } \\
\text { direct } \\
\text { effect }\end{array}$ & $\begin{array}{l}\text { Standard } \\
\text { ized } \\
\text { total } \\
\text { effect }\end{array}$ \\
\hline Shabit1<---Shabit3 & .441 & $* * *$ & 0.475 & 0.475 \\
Factor3<---Shabit1 & .241 & $* * *$ & 0.283 & 0.283 \\
Factor3<---Shabit3 & .178 & .006 & 0.225 & 0.359 \\
\hline
\end{tabular}

It can be concluded that students who use the tool ALEKS systematically as well as follow systematic study habits more often find that ALEKS is an effective tool than those who only use the tool systematically. It implies that to have a better impact of ALEKS on students' mathematics knowledge development, they should be encouraged to organize their learning tasks.

After establishing the positive effect of the variable Systematic study habits, the second hypothesis was investigated. For the second research aim (b) the null and alternate hypotheses are set as follows:

H2 ${ }_{0}$ : Null hypothesis: Study habits of male and female students do not differ significantly.

$\mathbf{H 2} \mathbf{A}_{\mathrm{A}}$ : Alternate hypothesis: Study habits of male and female students are not identical.

Results of Man-Whitney U-tests indicate that there is a significant difference between study habit1 (systematic study habit) and study habit 3 (habit of using ALEKS) of male and female students. (Sig 0.014 and 0.023 respectively). The mean rank for the variable systematic study habits as reported by male students is 115 and the same for female students is 94.

TABLE II: COMPARISON OF QUARTILE VALUES OF STUDY HABITS OF MALE AND FEMALE STUDENTS

\begin{tabular}{lllll}
\hline Study habits & Gender & \multicolumn{3}{l}{ Percentiles } \\
& & $25^{\text {th }}$ & $50^{\text {th }}$ & $75^{\text {th }}$ \\
\hline Systematic study habits & Female & 1.4 & 1.8 & 2.2 \\
& Male & 1.6 & 2.0 & 2.7 \\
Habits of using ALEKS & Female & 1.8 & 2.1 & 2.8 \\
& Male & 2.0 & 2.5 & 3.0 \\
\hline
\end{tabular}

Further exploration about quartile values reveals that more female students follow these two study routines very often than male students (Refer to the Table II). $75 \%$ female students have a mean score 2.2 for the variable systematics study habits. Whereas only $50 \%$ male students have a mean score 2 for the same variable. Recall that lower score represents the higher frequency of following the study habit. Almost $75 \%$ female students follow systematic routine very often and only $50 \%$ male students follow systematic study routine. The percentage of female students following systematic study very often are higher than male students. It can be concluded that male students need to be encouraged to follow systematic study habits more often.

There was no difference in other three study habits of male and female students, which are persistence, distraction and habit of seeking external help. The p-value for each of these tests are found to be $0.9,0.9$ and 0.4 respectively. This similarity in the two groups can be attributed to their neutral responses indicating that both groups follow these habits sometimes.

Similarity in the perceptions of male and female students is examined by setting the following hypothesis and applying the same test.

H3$_{\mathbf{0}}$ : Null hypothesis: Perceptions about the effect of ALEKS of male and female students do not differ significantly.

$\mathbf{H 3}_{\mathbf{A}}$ : Alternate hypothesis: Perceptions about the effect of ALEKS of male and female students are different.

Results of Man-Whitney U-tests indicate that male and female students have different perceptions about tutoring effect, effect on interest in mathematics and cognitive effect of ALEKS ( $p$-value $=0.000$ for each of these factors). The mean rank for the variable tutoring effect of ALEKS as reported by female students is 90 and the same for male students is 124 , whereas the mean rank for the variable cognitive effect of ALEKS are 92 and 119. The mean rank for the variable Affect reported by female students is 91 and that reported by male students is 123 . These rank values indicate that female students feel strongly about the effects of ALEKS on their learning than the male students. The perceptions of male and female students about the use of tools and beliefs about learning with tools are not statistically significant. (pvalue $=0.3$ and 0.4 respectively). The mean value of this factor was found to be equal to 2.6 and 2.8 for female and male students. Both groups are neutral about how to learn using the tools.

Activity theory framework suggests that not just the tool, but interactions with peers and other resources, such as study notes and other online resources helps the subject attain the learning goal [20]. The survey instrument measured the frequency of students' interactions with the tool and other resources. After analyzing these interactions, it was found that systematic study habits as mentioned above and systematic use of the tool have positive effects on the association between the subject (student) and the object (goal). These findings conform to the principles of Activity Theory. It was found that $72 \%$ of students agree that ALEKS is effective as a tutor, easy to use and they also agree that the use of ALEKS had a positive impact on their interest in mathematics. Students also think that ALEKS plays a major role in the development of their mathematical knowledge. As a learning tool, such as ALEKS, promotes understanding of mathematics, but its use proves more effective when a student is actively engaged in learning. Engaged learning will take place when students develop habits of organizing their learning tasks as well as their mental routines. Solving problems step by step on paper and taking notes during class activities are found to form routines of systematic study habits. Organizing learning tasks in the correct sequence and reading an explanation before solving the given problem are found to be habits of using ALEKS in a systematic manner.

\section{CONCLUSION AND FutURE DiRECTION}

This study investigated students' perceptions about learning mathematics using an intelligent tutor. Overall perceptions about learning with ALEKS as well as study 
habits of male and female students are found to be different Male students are found to be less organized and they should be encouraged to adopt systematic study habits more often.

Although the results are statistically significant they should be generalized carefully. The results can be generalized to the student population with a similar background. Students with a higher level of English language proficiency may exhibit different patterns of interactions and may have different perceptions.

This study can be extended further by collecting data from the same surveys as well as from the course gradebook. Correlation between students' perceptions, study habits and their coursework marks can be determined by combining the data from the surveys and the gradebook.

\section{REFERENCES}

[1] D. Nguyen, Y. Hsieh, and G. Allen, "The impact of web-based assessment and practice on students' mathematics learning attitudes," Journal of Computers in Mathematics and Science Teaching, vol. vol. 25, no. 3, pp. 251-279, 2006.

[2] T. Chen, M. Yunus, A. Suraya, W. Ali, and A. Bakar, "The effect of an intelligent tutoring system (ITS) on student achievement in Algebraic expression," vol. 1, no. 2, pp. 25-38, 2008.

[3] A. Bates and G. Poole, "Effective teaching with technology in higher education: Foundations for success," Jossey-Bass, An Imprint of Wiley, 2003.

[4] T. Cochrane, "Critical success factors for transforming pedagogy with mobile Web 2.0," British Journal of Educational Technology, vol. 45 , no. 1 , pp. $65-82,2014$.

[5] M. Kearneya, S. Schucka, and K. Burdenb, "Viewing mobile learning from a pedagogical perspective," Research in Learning Technology, vol. $20,2012$.

[6] L. Nguyen, S. Barton, and L. Nguyen, "Ipads in higher education-hype and hope," British Journal of Educational Technology, vol. 46, no. 1, pp. 190-2013, 2014

[7] C. Smith and D. Santori, "An exploration of ipad-based teaching and learning: how middle-grades teachers and students are realizing the potential," Journal of Research on Technology in Education, vol. 47, no. 3, pp. 173-185, 2015

[8] M. Mark and J. Greer, "Evaluation methodologies for intelligent tutoring systems," Journal of Interactive Learning Research, vol. 4, no. 2, pp. 129-142, 1993

[9] D. Wood and H. Wood, "Vygotsky, tutoring and learning," Oxford Review of Education, vol. 22, no. 1, pp. 5-16, 1996.

[10] M. Thelwall, "Computer-based assessment: a versatile educational tool," Computers and Education, vol. 34, no. 1, pp. 37-49, 2000.

[11] K. Sabo, R. Atkinson, R. Barrus, A. Joseph, and R. Perez, "Searching for the two sigma advantage: Evaluating algebra intelligent tutors," Computers in Human Behavior, vol. 29, no. 4, pp. 1833-1840, 2013.

[12] J. Anderson, C. Boyle, A. Corbett, and M. Lewis, "Cognitive modeling and intelligent tutoring," Artificial intelligence, vol. 42, no. 1, pp. 7-49, 1990.

[13] D. McArthur and C. Stasz, "An intelligent tutor for basic algebra," Santa Monica, CA: The Rand Corporation, 1989.

[14] E. Melis and J. Siekmann, "Activemath: An intelligent tutoring system for mathematics," Artificial Intelligence and Soft Computing, 2004, pp 91-101, 2004.

[15] Y. Xin, R. Tzur, C. Hord, J. Liu, J. Park, and L. Si, “An intelligent tutor-assisted mathematics intervention program for students with learning difficulties," Learning Disability Quarterly, 2007.
[16] A. Dani, "Students' patterns of interaction with a mathematics intelligent tutor: Learning analytics application," International Journal on Integrating Technology in Education, vol. 5, no. 2, June 2016.

[17] E. Yukselturk and S. Bulut, "Gender differences in self-regulated online learning environment," Educational Technology and Society, vol. 12 , no. 3 , pp. 12-22, 2009

[18] L. Kaino, "Technology in learning: Narrowing the gender gap," Eurasia Journal of mathematics, science and Technology Education, vol. 4, no. 3, pp. 263-268, 2008.

[19] I. Zualkernan, "Gender differences in a technology-based numeracy intervention in a developing country," in Proc. Global Humanitarian Technology Conference, 2015, pp. 414-419.

[20] Y. Engeström, "Expansive learning at work: Toward an activity theoretical reconceptualization," Journal of education and work, vol. 14 , no. 1 , pp. 133-156, 2001.

[21] K. Kutti, "Activity theory as a potential framework for human-computer interaction," in B. Nardi (Ed.), Context and Consciousness: Activity Theory and Human Computer Interaction, pp. 17-44, Cambridge: MIT, 1995.

[22] S. Barab, M. Evans, and E. Baek, "Activity theory as a lens for characterizing the participatory unit," Handbook of Research on Educational Communications and Technology, vol. 2, pp. 199-213, 2004.

[23] S. Batista, P. Behar, and L. Passerino, "Activity theory and m-learning in the teaching of Calculus," Ubiquitous and Mobile Learning in the Digital Age, vol. 8, no. 2, pp. 93-108, 2013.

[24] D. Jonassen, Revisiting Activity Theory as a Framework for Designing Student-Centered Learning Environments, pp. 89-121, New Jersey, United States of America: Lawrence Erlbaum Associates Inc., 2000.

[25] M. Koole, "A model for framing mobile learning," Mobile Learning. Transforming the Delivery of Education and Training, vol. 1, no. 2, pp. 25-47, 2009

[26] L. Uden, "Activity theory for designing mobile learning," International Journal of Mobile Learning and Organization, vol. 1, no. 1, pp. 81-102, 2007.

[27] G. Zurita and M. Nussbaum, "A conceptual framework based on activity theory for mobile CSCL," British Journal of Educational Technology, vol. 38, no. 2, pp. 211-235, 2007.

[28] G. Jackson, A. Graesser, and D. McNamara, "What students expect may have more impact than what they know or feel," AIED, pp. 73-80, 2009.

[29] A. Jansen, J. DiNapoli, and K. McKenney, "Reconsidering affect in mathematics education," Journal for Research in Mathematics Education, vol. 48, no. 1, pp. 106-110, 2017.

[30] M. Berger, "A semiotic view of mathematical activity with a computer algebra system," Revista latinoamericana de investigación en matemática educativa, vol. 13, no. 2, pp. 159-186, 2010.

[31] F. Hitt and C. Kieran, "Constructing knowledge via a peer interaction in a CAS environment with tasks designed from a task-techniquetheory perspective," International Journal of Computers for Mathematical Learning, vol. 14, no. 2, pp. 121-152, 2009

[32] R. M. Warner, Applied Statistics: From Bivariate through Multivariate Techniques, Sage: New York, 2008.

[33] T. Little, N. Card, J. Bovaird, K. Preacher, and C. Crandall, "Structural equation modeling of mediation and moderation with contextual factors," Modeling Contextual Effects in Longitudinal Studies, vol. 1, pp. 207-230, 2007

Anita Dani holds a Ph.D. in mathematics education and masters in mathematics. She has taught pure and applied mathematics courses as well as courses in algorithms and database management systems in international Universities in the United Arab Emirates. Her research interests include data mining, learning analytics, mobile learning and educational technology. 